\title{
Nitrogen-boron Dipolar-doped Nanocarbon as a High-efficiency Electrocatalyst for Oxygen Reduction Reaction
}

\author{
Taizhong Huang ${ }^{\mathrm{a}, 1, *}$, Shun Mao ${ }^{\mathrm{b}, 1}$, Ming Qiu ${ }^{\mathrm{c}, 1}$, Ou Mao ${ }^{\mathrm{d}}$, Chris Yuan ${ }^{\mathrm{c}}$, Junhong Chen ${ }^{\mathrm{c}, *}$ \\ a Shandong Provincial Key Laboratory of Fluorine Chemistry and Chemical Materials, School of Chemistry and Chemical Engineering, University of Jinan, Jinan \\ 250022, China \\ b State Key Laboratory of Pollution Control and Resource Reuse, College of Environmental Science and Engineering, Tongii University, 1239 Siping Road, \\ Shanghai 200092, China \\ ${ }^{\mathrm{c}}$ Department of Mechanical Engineering, University of Wisconsin-Milwaukee, 3200 North Cramer Street, Milwaukee, WI 53211, USA \\ d Nano Technology Limited, 50 California St., Suite 2920, San Francisco, CA 95439, USA
}

\section{A R T I C L E I N F O}

\section{Article history:}

Received 12 April 2016

Received in revised form 31 October 2016

Accepted 31 October 2016

Available online $\mathrm{xxx}$

\section{Keywords:}

Carbon nanotube

Oxygen reduction reaction

Nitrogen-boron dipolar doping

Electrocatalyst

\section{A B S T R A C T}

Nitrogen-boron dipolar-doped commercial multi-walled carbon nanotubes (MWCNTs) were prepared and demonstrated as a high-efficiency and low-cost electrocatalyst for oxygen reduction reaction (ORR). The resulting nitrogen-boron dipolar-doped MWCNTs (N, B-CNTs) exhibit a doubled peak current density and a small negative shift in onset potential in ORR compared with the commercial Pt/C catalyst. The doped nitrogen and boron form n- and p-type active centers in the N, B-CNT, respectively, which can weaken the $\mathrm{O}-\mathrm{O}$ stretching and extend the $\mathrm{O}-\mathrm{O}$ bond length in oxygen reduction reaction. Firstprinciples calculations reveal that the $\mathrm{O}_{3} \mathrm{H}^{-}$and $\mathrm{O}_{3} \mathrm{H}_{2}$ transitional states of oxygen are formed on the doped nitrogen and boron, which promotes the four-electron reaction in ORR.

(c) 2016 Elsevier Ltd. All rights reserved.

\section{Introduction}

High cost of traditional anode and cathode catalysts in fuel cells, e.g., precious metals and alloys such as Pt, Pd-based alloys, is an obstacle for their wide application [1-8]. To reduce the cost of fuel cells, many non-precious metal catalysts, especially catalysts for oxygen reduction reaction (ORR) in anode, have been widely investigated [9-11]. This includes transition metal-based carbides, nitrides, and oxides [11-22]. In addition to transition metal-based catalysts, carbon-based nanomaterials, as represented by carbon nanotubes (CNTs) and graphene, have attracted great attention due to their unique structures and versatile characteristics [23-25].

The catalytic activity of pristine CNTs in ORR is relatively weak, but its catalytic performance could be promoted by doped elements such as nitrogen, sulfur, transitional elements, etc. [26-33]. For instance, nitrogen-doped vertically-aligned CNTs were reported to have outstanding catalytic activity, good longterm stability and tolerance to the methanol crossover effect than platinum for ORR in alkaline fuel cells [34]. In one review article on

\footnotetext{
* Corresponding authors.

E-mail addresses: chm_huangtz@ujn.edu.cn (T. Huang), jhchen@uwm.edu (J. Chen).

1 The authors contributed equally to this work.
}

boron- and nitrogen-doped CNTs, Panchakarla et al. discussed that the doping method could be an efficient route to enhance the catalytic activity of CNTs [35]. Compared with nitrogen doping, the boron doping was usually performed with a chemical vapor deposition (CVD) method using borane as the boron source [36]. However, the toxicity of borane and the low efficiency of the CVD method have made the large-scale production of boron-doped CNT a great challenge. In addition, since the catalytic performance was determined by the state of doped elements in the catalyst [37], developing a facile method to controllably dope nitrogen and boron into nanocarbons is highly needed.

Here, we report a facile and low-cost method to prepare dipolar-doped nitrogen and boron MWCNTs with surprisingly high catalyst performance for ORR. The peak current density of oxygen reduction for the nitrogen and boron dipolar-doped CNTs (N, B$\mathrm{CNTs}$ ) is more than twice higher than that of the commercial $\mathrm{Pt} / \mathrm{C}$, and the onset potential of the N, B-CNT is only $50 \mathrm{mV}$ lower than that of $\mathrm{Pt} / \mathrm{C}$, indicating an outstanding performance of the $\mathrm{N}, \mathrm{B}-$ CNTs. Density functional theory (DFT) calculations show that the dipolar-doped nitrogen and boron promote the four-electron reaction in ORR, thus enhance the catalytic activity of the catalyst in ORR. We believe this method could be applied to other nanocarbon materials, e.g., graphene, or their hybrids to prepare high-performance and low-cost electrocatalysts. 


\section{Experimental Details}

\subsection{Materials synthesis}

The preparation of boron-doped CNTs (B-CNT), nitrogen-doped CNTs (N-CNT), and N, B-CNT are illustrated in Fig. 1. The CNTs were provided by Nano Technology Ltd. and labelled as pristine CNTs and adopted without any treatment. In a typical experiment, $300 \mathrm{mg}$ of pristine CNTs were treated for $30 \mathrm{~min}$ in $8 \mathrm{M}$ nitric acid at $40^{\circ} \mathrm{C}$ with sonication. The treated CNTs were dried at $333 \mathrm{~K}$ and $-0.08 \mathrm{MPa}$ (vacuum) for 12 hours, and then heated up to $800^{\circ} \mathrm{C}$ under ammonia atmosphere to obtain N-CNTs. To prepare B-CNT and $\mathrm{N}, \mathrm{B}-\mathrm{CNT}, 50 \mathrm{mg} \mathrm{H} \mathrm{BO}_{3}$ were added to the CNT solution with nitric acid and dried. The obtained mixture was divided into two portions and heated to $800^{\circ} \mathrm{C}$ for two hours under hydrogen and ammonia atmosphere, respectively. The heat-treated samples were washed with $1.0 \mathrm{M} \mathrm{NaOH}$ and DI water to remove the residue $\mathrm{H}_{3} \mathrm{BO}_{3}$ and boron oxide. Then B-CNTs and N, B-CNTs were obtained.

\subsection{Structure Characterization}

The morphology of the as-prepared samples and the selected area electron diffraction (SAED) patterns were obtained using a Hitachi (H 9000 NAR) transmission electron microscope (TEM) and a Hitachi (S-4800) scanning electron microscope (SEM) equipped with an energy-dispersive spectroscopy analyzer. Powder X-ray diffraction (XRD) was performed on a Scintag XDS 2000. X-ray powder diffractometer with monochromatized $\mathrm{CuK} \alpha$ radiation $(\lambda=1.5418 \AA)$. The data were collected between scattering angles

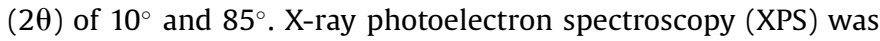
conducted using an HP 5950A ESCA spectrometer with an Mg K $\alpha$ source. $\mathrm{N}_{2}$ adsorption-desorption measurements were carried out at $77 \mathrm{~K}$ using a Quantachrome Autosorb gas-sorption system to determine the specific surface area of pristine CNT, N-CNT, and N, B-CNT.

\subsection{Electrochemical measurements}

The electrochemical tests were carried out in $1 \mathrm{M} \mathrm{KOH}$ solution at room temperature using a $\mathrm{CHI} 760 \mathrm{E}$ electrochemical workstation (CHI Inc., USA). The three-electrode cell consists of an $\mathrm{Ag} / \mathrm{AgCl}$ electrode as the reference electrode, a graphite electrode as the counter-electrode, and a glassy carbon electrode with catalysts as the working electrode. To prepare the working electrode, $3.0 \mathrm{mg}$ prepared catalyst was mixed with $50 \mu$ l Nafion solution $(5.0 \%$ Nafion in ethanol) and $450 \mu \mathrm{l}$ DI water. The mixture was sonicated for $30 \mathrm{~min}$ to obtain a black ink. Then, $5.0 \mu \mathrm{l}$ ink was taken and

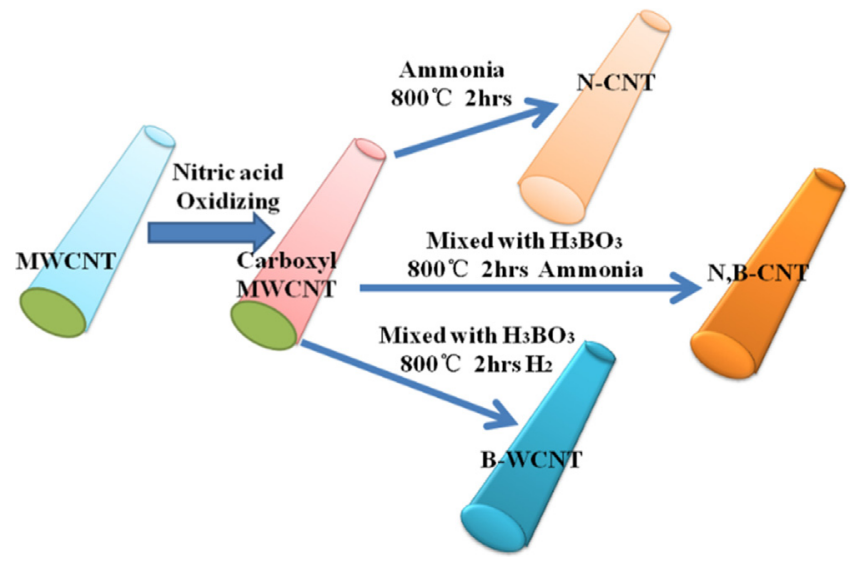

Fig. 1. Preparation process for N-CNT, B-CNT, and N, B-CNT. dropped onto a glassy carbon electrode with a diameter of $3 \mathrm{~mm}$ and fully dried. Before the electrochemical tests, the working electrode was kept in an Ar-saturated electrolyte by cycling the potential from 0.2 to $-0.8 \mathrm{~V}$ at a scan rate of $0.1 \mathrm{~V} / \mathrm{s}$ until reproducible results appeared. Thereafter, the electrolyte was saturated with oxygen and cyclic voltammogram tests for ORR were carried out and recorded from 0.2 to $-0.8 \mathrm{~V}$ at sweeping rates of $0.1,0.05,0.02,0.01$, and $0.005 \mathrm{~V} / \mathrm{s}$. Linear-sweep voltammograms (LSV) tests were conducted from 0 to $-0.4 \mathrm{~V}$ at a sweeping rate of $0.005 \mathrm{~V} / \mathrm{s}$. The Tafel and current(i)-time(t) tests were also conducted at the same sweeping rate. The rotate disc and rotate ring disc electrocatalysis tests were conducted from 0.0 to $-0.4 \mathrm{~V}$ (vs. $\mathrm{Ag} / \mathrm{AgCl}$ ) by an $\mathrm{RDE}-3 \mathrm{~A}$ electrode.

\section{Results and discussions}

\subsection{N, B-CNT structure}

The successful synthesis of N, B-CNT was confirmed by TEM images and XPS spectra. Fig. 2a and b shows the TEM and highresolution TEM (HRTEM) images of the pristine CNTs. It is clearly observed that the surface of pristine CNT is quite smooth [38-40]. In comparison, Fig. $2 \mathrm{c}$ reveals that the surface of $\mathrm{N}, \mathrm{B}-\mathrm{CNT}$ is much rougher than that of pristine CNTs, which is likely attributed to the doped nitrogen and boron. The HRTEM images of N, B-CNT (Fig. 2d) shows a stair-like structure, likely originating from the oxidation of CNTs in nitric acid with sonication. The SAED patterns of CNT and $\mathrm{N}, \mathrm{B}-\mathrm{CNT}$ are shown in the insets of Fig. 2a and c, respectively, which are consistent with MWCNT structures. Fig. S1a-b and c-d in Supplementary Information show the TEM and HRTEM images of N-CNT and B-CNT, respectively. Similar structures were also observed. For each layer of CNTs, the carbon atoms are normally in $\mathrm{sp}^{2}$ electron hybridization, which promotes the formation of a perfect hexagonal carbon ring structure and eventually forms a smooth carbon layer. The doped boron and nitrogen in the hexagonal structure granulate the surface of CNTs, leading to a rougher surface. Calculations on the structure of nitrogen-doped CNT also indicated that nitrogen-doping could granulate the surface of CNT [34,41]. Fig. S1f in Supplementary Information shows the XRD patterns of pristine CNT and N, B-CNT. The XRD patterns of N, B-CNT was indexed from the Joint Committee on Powder Diffraction Standards (JCPDS) (\#35-1292), which indicates that the N, B-CNT has a hexagonal structure with a nominated $(\mathrm{NB})_{0.26} \mathrm{C}_{0.74}$ composition.

The XPS survey spectra of pristine CNT, N-CNT, B-CNT, and N, $\mathrm{B}-\mathrm{CNT}$ are shown in Fig. 2e. The XPS survey spectra clearly demonstrate the successful doping of N or/and B in CNTs. Fig. $2 \mathrm{f}-\mathrm{h}$ shows the high-resolution XPS spectra of $\mathrm{C} 1 \mathrm{~s}, \mathrm{~N} 1 \mathrm{~s}$, and B1s of $\mathrm{N}$, B-CNT, which further confirm the successful doping of nitrogen and boron. The discrepancy between the observed $\mathrm{C} 1 \mathrm{~s}$ signal and the slight shifting of perfect $\mathrm{sp}^{2}$ hybridized graphitic carbon were attributed to the disordered graphitic network [42]. The $\mathrm{N}-\mathrm{B}$ and $\mathrm{N}-\mathrm{C}$ bond in the N1s spectra (Fig. $2 \mathrm{~g}$ ) and $\mathrm{B}-\mathrm{N}$ and $\mathrm{B}-\mathrm{C}$ bonds in the B1s spectra (Fig. 2h) are in a good accordance with the XPS spectra of C1s. The UV-vis absorption spectra, Raman spectra, and Fourier Transform infrared spectroscopy (FT-IR) results are provided in Supplementary Information Fig. S3. These results also confirm the successful doping of nitrogen and/or boron in CNTs. The specific surface areas of the samples tested by the BrunauerEmmett-Teller (BET) method are provided in Supplementary Information Fig. S3. The specific surface areas of pristine CNT, $\mathrm{N}-\mathrm{CNT}$ and N, B-CNT are $268 \mathrm{~m}^{2} / \mathrm{g}, 281 \mathrm{~m}^{2} / \mathrm{g}$, and $324 \mathrm{~m}^{2} / \mathrm{g}$, respectively. The increased specific surface areas are likely attributed to the doped nitrogen- and boron-induced granulation of CNTs. 

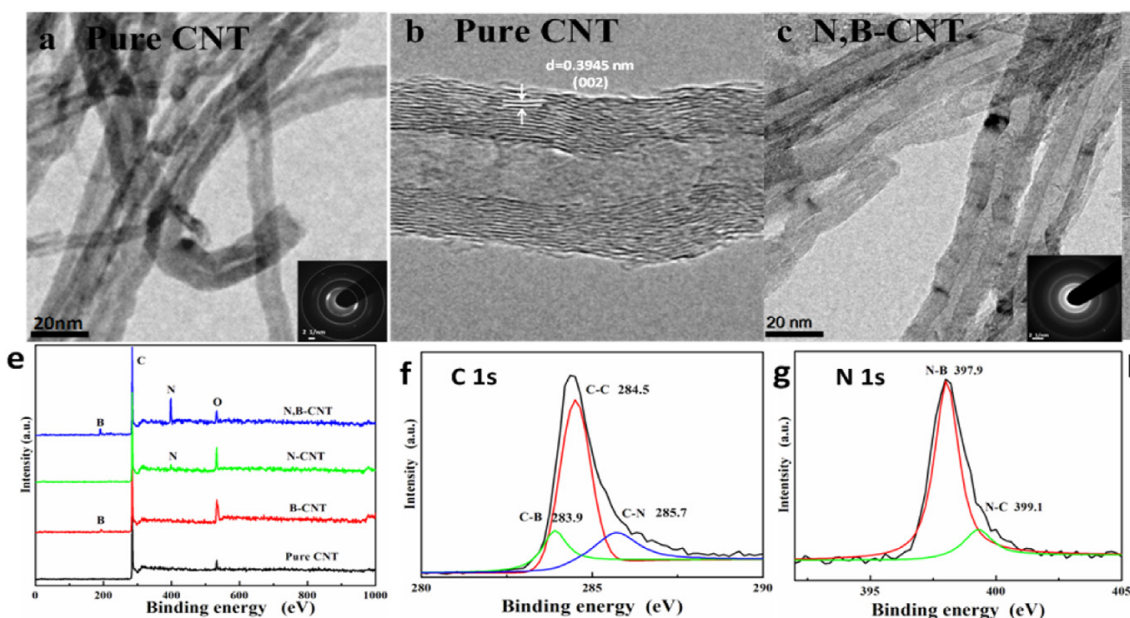

d N,B-CNT
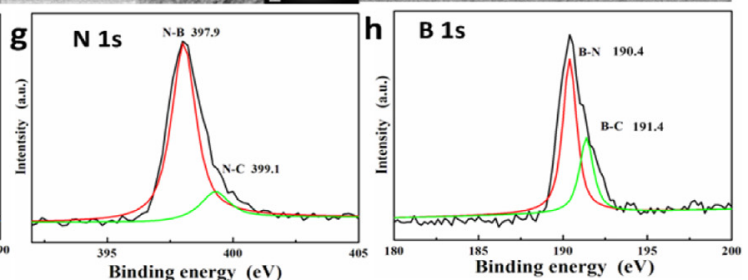

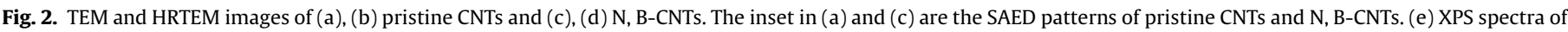
pristine CNT, B-CNT, N-CNT, and N, B-CNT. (f)-(h) High-resolution XPS spectra of C1s, N1s, and B1 s in N, B-CNT.

\subsection{Electrocatalytic performance study}

The cyclic voltammetry (CV) tests in Fig. 3a-e show that no oxygen reduction peaks were detected in the argon-saturated $1 \mathrm{M}$ $\mathrm{KOH}$ solution for all samples, and on the contrary, the oxygenreduction peaks were clearly observed in the oxygen-saturated $1 \mathrm{M}$ $\mathrm{KOH}$ solution. Based on the CV tests, the onset potential and peak current density of ORR for each catalyst are obtained and shown in Fig. 3f. The pristine CNT shows the smallest current density and the lowest onset potential among all the catalysts. The catalytic activity of pristine CNT is usually attributed to the structure defects and the open tips of CNTs. Interestingly, the catalytic activity of pristine CNTs are greatly enhanced by the doped nitrogen or/and boron. The ORR peak current intensities of nitrogen- or/and borondoped CNTs were higher than that of pristine CNTs and even higher than that of $\mathrm{Pt} / \mathrm{C}$ catalysts. Specifically, the peak current density of $\mathrm{N}, \mathrm{B}-\mathrm{CNT}$ is more than two times higher than that of the $\mathrm{Pt} / \mathrm{C}$ catalyst.
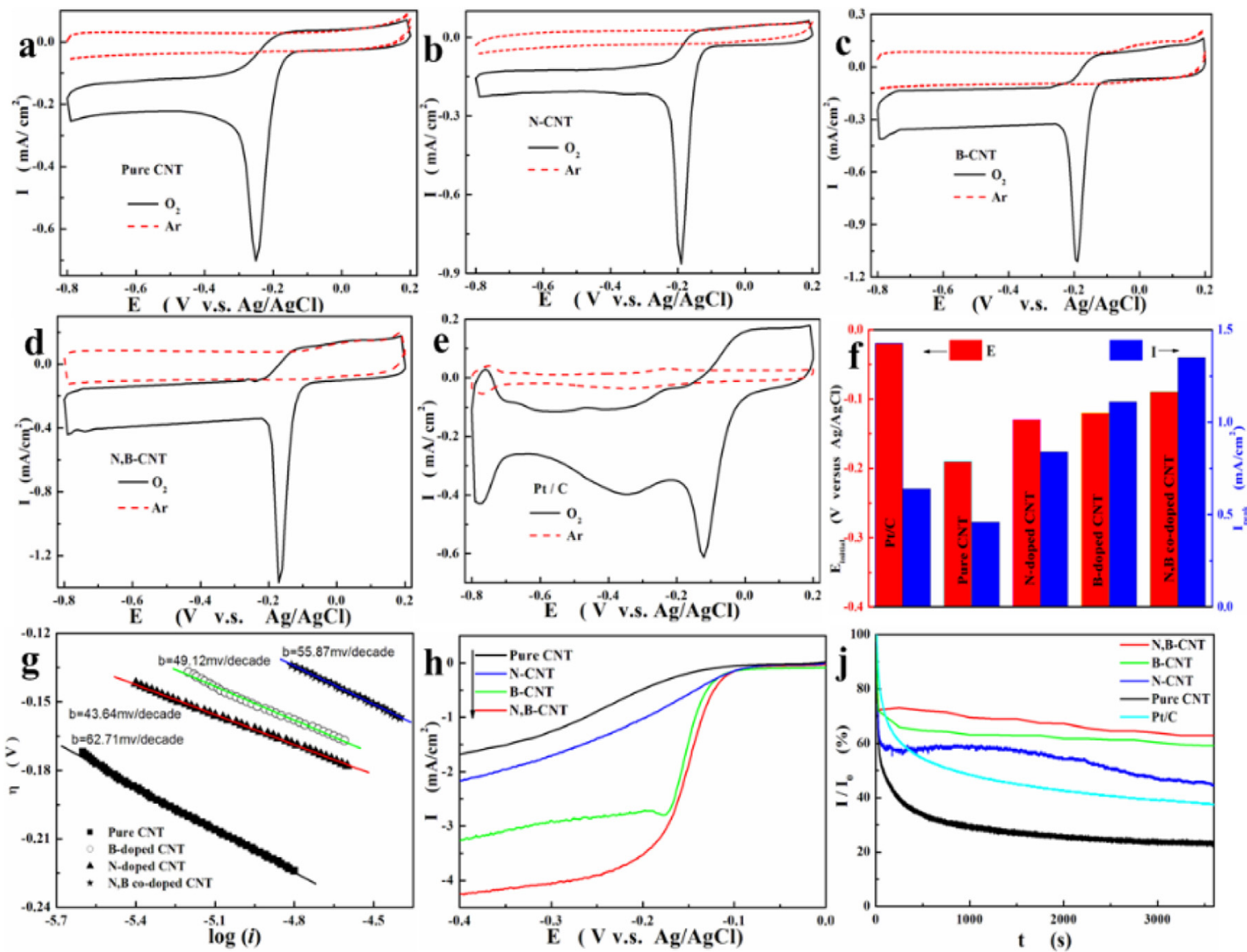

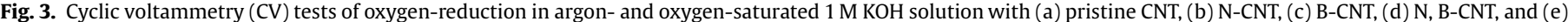

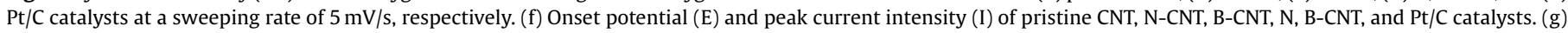
Tafel slope, (h) linear scanning voltammetry (LSV), and (j) Current (i)-time (t) chronoamperometric results of pristine CNT, N-CNT, B-CNT, and N, B-CNT, respectively. 
The onset potential is another critical parameter in evaluating the ORR catalytic activity. As shown in Fig. 3f, the Pt/C catalyst has the smallest onset potential close to $-0.02 \mathrm{~V}$ ( $\mathrm{vs}$. $\mathrm{Ag} / \mathrm{AgCl}$ ), indicating the high catalytic activity of Pt/C in ORR. However, the N, B-CNT also shows a relatively good onset potential, which is only $50 \mathrm{mV}$ lower than that of the $\mathrm{Pt} / \mathrm{C}$ catalyst. Compared with pristine CNT, N-CNT, and B-CNT, the onset potential of N, B-CNT is better, which is attributed to co-doped nitrogen and boron [43-46].

The plotted polarization curves shown in Fig. $3 \mathrm{~g}$ are known as "Tafel plots" and are derived from the Tafel equations shown below:

$\eta=\mathrm{b} \cdot \lg \frac{i}{i_{0}}$, where $\mathrm{b}=\frac{2.3 \mathrm{RT}}{(1-\alpha) \mathrm{nF}}$,

where $\eta$ refers to the electrode polarization potential, $b$ is tafel slope, $i$ is the experimentally obtained electrode current, $i_{0}$ is the exchange current density, $\alpha$ is electron transfer constant, $\mathrm{R}$ is gas constant $8.314 \mathrm{~J} /(\mathrm{mol} \cdot \mathrm{K})$, $\mathrm{T}$ is test temperature in $\mathrm{K}, \mathrm{F}$ is Faraday constant $(96,485 \mathrm{C} / \mathrm{mol})$, and $\mathrm{n}$ is the electron transfer number. Based on calculations and $\mathrm{CV}$ results, the Tafel slopes, charge transfer coefficients, electron exchange current densities, onset potential, and half-wave potentials of the samples are obtained and shown in Table 1. It is found that the onset potential $\left(\mathrm{E}_{0}\right)$, halfwave potential $\left(E_{1 / 2}\right)$, and peak current intensities increase in the order of pristine CNT, N-CNT, B-CNT, and N, B-CNT. The exchange current density $\left(i_{0}\right)$ also increased in the same order, except for $\mathrm{N}$ CNT. The exchange current density of N, B-CNT is the largest among the catalysts. The enhanced current density is closely related to the doped elements in CNTs. In N, B-CNT, The doped boron presented a positive electron active center and the doped nitrogen presents a negative electron center [47]. The electronic structure of the surface carbon layer was tailored by the doped nitrogen and boron, which improved the catalytic performance of the CNTs [48]. On the other hand, the dipolar-doped nitrogen and boron lead to more defects in N, B-CNT, which served as active sites for oxygen adsorption and reduction. In addition, the nitrogen-doped graphitic layer possesses a faster charge-transfer rate at the electrode/electrolyte interface, which is favourable to the electron transfer of ORR [49-51]. Supplementary Information Fig. S4 shows the CVs of the samples at different sweeping rates and the correlation of the peak current density and the square root of sweeping rate. It is clearly observed that, for each catalyst, the peak current density linearly increases with the increase of sweeping rate, which means that the oxygen reduction is controlled by the diffusion of oxygen on the electrode surface.

Fig. 3h shows the LSV results of ORR, in which the onset potential shifts to positive direction and current density increases in the order of pristine CNT, N-CNT, B-CNT, and N, B-CNT. Fig. $3 \mathrm{j}$ shows the current(i)-time(t) chronoamperometric tests of the catalysts. The i-t performances of N, B-CNT is the best among the samples after 3500 seconds test and is much better than that of the $\mathrm{Pt} / \mathrm{C}$ catalyst, which indicates that nitrogen- and boron-doping may also help enhance the long-term stability of the catalyst. The $\mathrm{Pt} / \mathrm{C}$ catalyst with a loading of $20 \% \mathrm{Pt}$ was obtained from Umicore Ltd. (Germany).

Table 1

Electrocatalytic activity and kinetic parameters of the catalysts for ORR.

\begin{tabular}{lllllll}
\hline Catalyst & $\mathrm{E}_{0}(\mathrm{~V})$ & $\mathrm{E}_{1 / 2}(\mathrm{~V})$ & $i_{f}\left(\mathrm{~mA} / \mathrm{cm}^{2}\right)$ & $\mathrm{b}(\mathrm{mV} / \mathrm{dec})$ & $\alpha$ & $i_{0}\left(\mathrm{~mA} / \mathrm{cm}^{2}\right)$ \\
\hline Pristine CNT & -0.189 & -0.222 & 0.46 & 62.71 & 0.552 & $4.59 \times 10^{-9}$ \\
N-CNT & -0.135 & -0.168 & 0.84 & 43.64 & 0.368 & $2.15 \times 10^{-9}$ \\
B-CNT & -0.124 & -0.154 & 1.11 & 49.12 & 0.491 & $9.61 \times 10^{-9}$ \\
N, B-CNT & -0.070 & -0.131 & 1.35 & 55.87 & 0.584 & $6.26 \times 10^{-8}$ \\
Pt/C & -0.020 & -0.082 & 0.65 & - & - & - \\
\hline
\end{tabular}

Fig. 4 shows the rotating-disk electrode (RDE) voltammogram tests and corresponding Koutecky-Levich plots of the catalysts at different potentials. The oxygen-reduction current density increased with increasing rotating speed, which originated from the enhanced oxygen diffusion on the electrode surface [52]. Based on the RDE tests, the electron transfer number $(n)$ of ORR can be calculated according to Koutecky-Levich theory [53]:

$\frac{1}{\mathrm{I}}=\frac{1}{\mathrm{I}_{\mathrm{k}}}+\frac{1}{\mathrm{I}_{\mathrm{D}}}=\frac{1}{\mathrm{I}_{\mathrm{k}}}+\frac{1}{\mathrm{~B} \omega^{1 / 2}}$

where $I$ is the experimentally obtained current, IK refers to the mass-transport-free kinetic current, $I_{D}$ refers to the measured diffusion-limited current and $\omega$ is the electrode rotating speed. To calculate the electron transfer number, following equations are used along with Eq. (2):

$\mathrm{B}=0.62 \mathrm{nF}\left(\mathrm{D}_{0}\right)^{\frac{2}{3}} \boldsymbol{\nu}^{-\frac{1}{6}} \mathrm{C}_{0}$,

$\mathrm{I}_{\mathrm{k}}=\mathrm{nF} \kappa \mathrm{C}_{0}$,

where $\mathrm{F}$ is the Faraday constant $(96485 \mathrm{C} / \mathrm{mol}), \mathrm{D}_{0}$ is the diffusion coefficient of $\mathrm{O}_{2}$ in $1 \mathrm{M} \mathrm{KOH}\left(1.9 \times 10^{-5} \mathrm{~cm}^{2} / \mathrm{s}\right), \mathrm{v}$ is the kinetic viscosity $\left(0.01 \mathrm{~cm}^{2} / \mathrm{s}\right)$, and $\mathrm{C}_{0}$ is the bulk concentration of $\mathrm{O}_{2}$ $\left(1.2 \times 10^{-6} \mathrm{~mol} / \mathrm{cm}^{3}\right)$. The constant 0.62 is adopted when the rotation speed $\omega$ is expressed in rad/s. Fig. $4 \mathrm{~b}, \mathrm{~d}$, f, and h shows the calculated electron transfer number of each catalyst at different potentials. The calculated electron transfer number of the catalysts distributed between two and four, which indicates the reduction of $\mathrm{O}_{2}$ with the catalysts is a mixed process of two electron and four electron reactions. For general comparison, the electron transfer numbers of N, B-CNT are larger than other catalysts and more close to four, indicating the synergistic effect of dipolar-doped nitrogen and boron in N, B-CNT enhanced the four-electron oxygenreduction reaction. Similar phenomenon was also reported in nitrogen- and boron-doped graphene catalyst, in which the electron transfer number was believed to be influenced by the doped elements [54]. The electron transfer numbers were also calculated with rotate ring disc electrode (RRDE) tests, as shown in Supplementary Information Fig. S5. The calculated results are in good accordance with the RDE results.

\subsection{First-principles calculations}

The effects of doped boron and nitrogen on ORR catalytic performance of CNT were calculated by B3LYP hybrid density functional theory (DFT, DMol3). The details of the calculations are provided in Supplementary Information. The calculated Mülliken charge distribution for the $\mathrm{N}, \mathrm{B}-\mathrm{CNT}$ and schematic representations of possible reaction patterns on the surface of $\mathrm{N}$, B-CNT are displayed in Fig. 5A.

The modeling results indicate that boron and carbon atoms that adjacent to the nitrogen atom have a stronger positive charge density to counterbalance the strong electronegativity of nitrogen atom compared with that of pristine CNT and B-CNT structures [55-57]. The doped nitrogen in CNT can exist in both p-type and ntype states in the form of pyrrolic, pyridinic, and graphitic [58,59]. The pyrrolic nitrogen was $\mathrm{sp}^{3}$ hybridized, and pyridinic and graphitic nitrogen were $\mathrm{sp}^{2}$ hybridized. The doped nitrogen enhanced the oxygen reduction activity, which was proved by both theoretical calculations and experimental tests [19,44,60]. DFT calculation, alongside local $\mathrm{N}$-configuration mappings during plasma treatment, reveals that the origin of the improved capacitance was a certain $\mathrm{N}$-configuration at basal planes $[43,61]$. Electrochemical characterizations clearly demonstrated excellent electrocatalytic activity of N-RGO for oxygen reduction in 

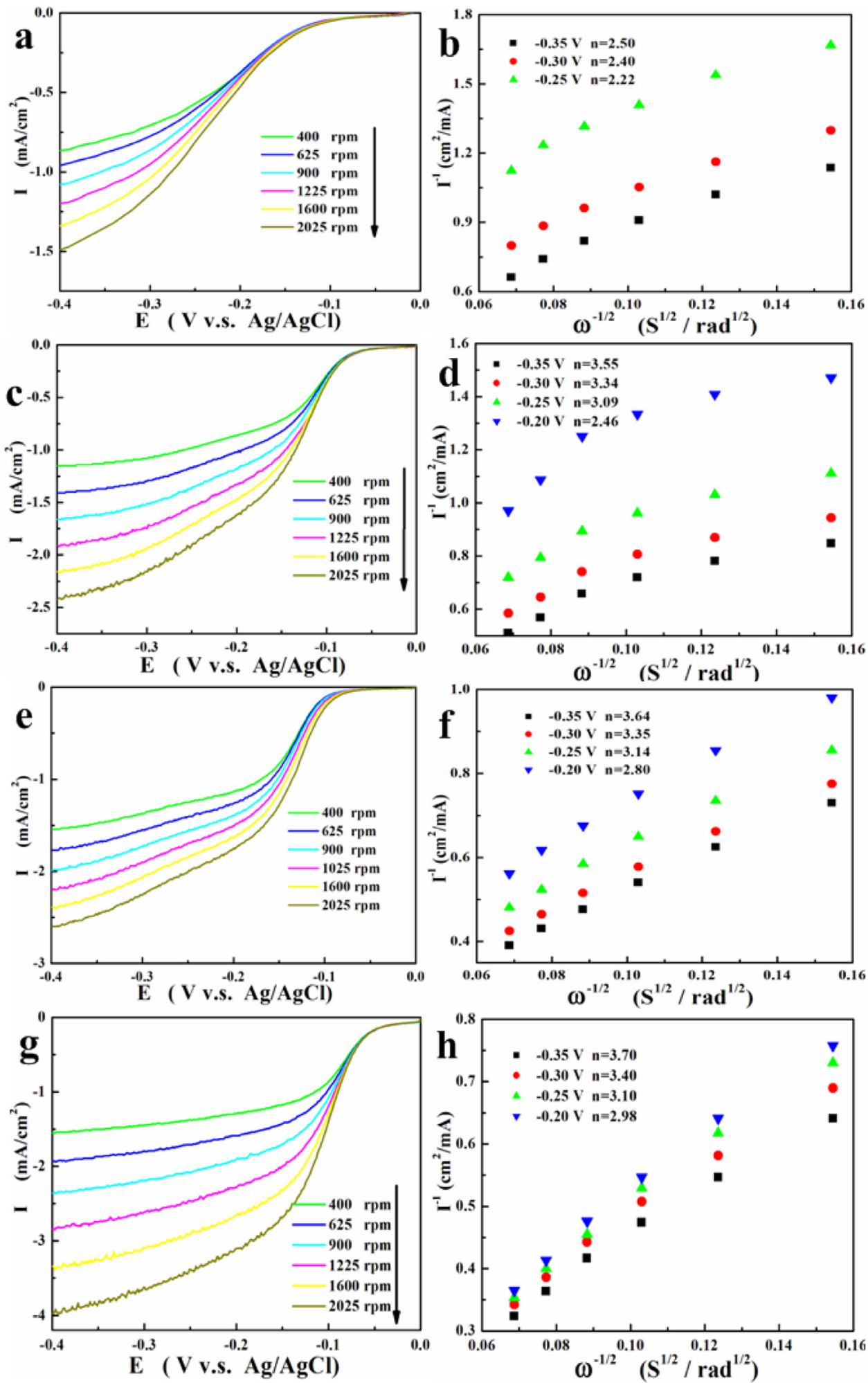

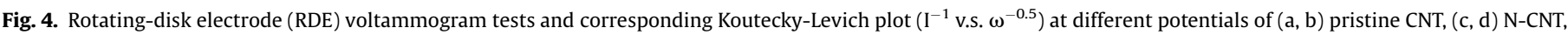
(e, f) B-CNT, and (g, h) N, B-CNT.

alkaline electrolytes via a four-electron pathway. The total content of graphitic and pyridinic nitrogen atoms plays a key role in enhancing the electrocatalytic activity for ORR. The nitrogeninduced strong positive ionicity of boron and carbon atoms enhances the chemisorptions of $\mathrm{O}_{2}$ and $\mathrm{OH}^{-}$. The $\mathrm{O}_{2}$ has more favorite priority to be adsorbed on the boron atom than $\mathrm{OH}^{-}$and $\mathrm{H}_{2} \mathrm{O}$ while the $\mathrm{OH}^{-}$adsorbs at the end of $\mathrm{O}_{2}$ to have an $\mathrm{O}_{3} \mathrm{H}^{-}$ configuration. This chemsorption will transit to a more stable state while the two $\mathrm{OH}^{-}$are adsorbed on the adjacent carbon atoms of nitrogen atom and an $\mathrm{O}_{2} \mathrm{H}^{-}$on the boron atom in the water. The curve illustrates the activation energy changes in the process of oxygen reduction. Based on the calculation, the obtained oxygen reduction course may include the following reactions: 

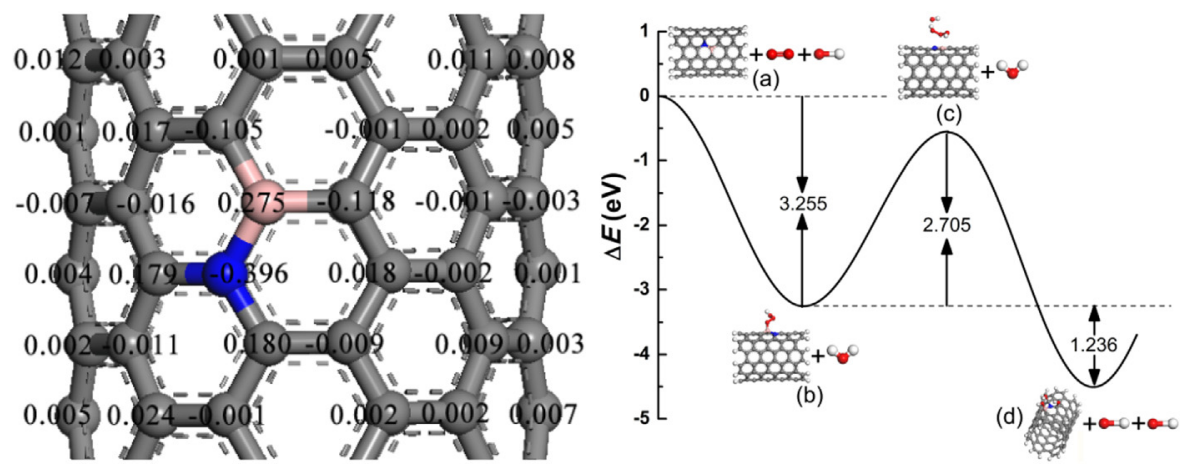

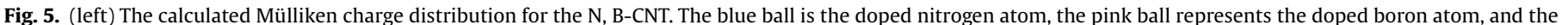
grey balls are carbon atoms. (right) Schematic representations of possible reaction patterns on the surface of N, B-CNT.

$\mathrm{O}_{2}+\mathrm{OH}^{-}=\mathrm{O}_{3} \mathrm{H}^{-}$

$\mathrm{O}_{2}+\mathrm{H}_{2} \mathrm{O}+2 \mathrm{e}^{-}=\mathrm{OH}^{-}+\mathrm{HO}_{2}$

$\mathrm{O}_{3} \mathrm{H}^{-}+\mathrm{H}_{2} \mathrm{O}=\mathrm{OH}^{-}+\mathrm{O}_{3} \mathrm{H}_{2}$

$\mathrm{O}_{3} \mathrm{H}_{2}+\mathrm{H}_{2} \mathrm{O}+4 \mathrm{e}^{-}=4 \mathrm{OH}^{-}$(main reaction)

$\mathrm{O}_{3} \mathrm{H}^{-}+2 \mathrm{H}_{2} \mathrm{O}+2 \mathrm{e}^{-}=3 \mathrm{OH}^{-}+\mathrm{H}_{2} \mathrm{O}_{2}$

Reaction (5) first happened as shown in Fig. 5B (a) and (b), where oxygen molecular first absorbed on N, B-CNT. Reactions (7) and (8) are corresponding to Fig. 5B (c). Reaction (9) is corresponding to Fig. 5B (d), where the $\mathrm{H}_{2} \mathrm{O}_{2}$ are absorbed on the surface of $\mathrm{N}, \mathrm{B}-\mathrm{CNT}$ and eventually transit to two $\mathrm{OH}^{-}$. The active energy changes with the change of oxygen transitional state. B-CNT showed higher oxygen reduction performance compared with N-doped carbon-nanotube. Quantum chemical calculations on boron-doped graphene proved that the doped boron weakened $\mathrm{O}-\mathrm{O}$ stretching and extended the $\mathrm{O}-\mathrm{O}$ bond length, which eventually enhanced the oxygen reduction catalytic characteristics $[62,63]$. The doped-boron atoms also introduced holes to the graphene, changing the electronic structure of the planer sheet and resulting in local positive charge centers. The positive charged areas on the flat surface attracted pyridine to form strong chemical bonds at the interface and promoted the adsorption of $\mathrm{OOH}^{-}$on itself, facilitating oxygen reduction reaction.

\section{Conclusions}

The catalytic performance of pristine CNT, N-CNT, B-CNT, and N, $\mathrm{B}-\mathrm{CNT}$ in oxygen reduction reaction was investigated. The N, B-CNT catalyst exhibited the highest activity and stability for ORR in alkaline solutions. The dipolar-doped nitrogen and boron form n-type and p-type active centers, which promote the four-electron transfer oxygen reduction reaction. This facile method used to prepare nitrogen and boron co-doped CNTs represents a general approach to synthesize high-efficiency and durable electrocatalysts for a wide range of electrochemical reactions.

\section{Acknowledgements}

Financial support for this work was provided by the U.S. Department of Energy (DE-EE0003208); the Research Growth Initiative Program of the University of Wisconsin-Milwaukee
(UWM); Shandong Provincial Natural Science Foundation, China (No. ZR2015EM044); and the Science Development Project of Shandong Province China (No. 2014GGX104004). The authors thank Professor M. Gajdardziska-Josifovska for TEM access at the UWM HRTEM Laboratory, Dr. H. A. Owen for technical support with SEM analyses, Dr. S. E. Hardcastle for technical support with XRD and XPS analyses, and Mr. Jianyang Li for help with the structure diagram.

\section{Appendix A. Supplementary data}

Supplementary data associated with this article can be found, in the online version, at http://dx.doi.org/10.1016/j.electacta.2016. 10.201.

\section{References}

[1] E. Antolini, Catalysts for direct ethanol fuel cells, Journal of Power Sources 170 (2007) 1-12.

[2] D.J. Berger, Fuel Cells and Precious-Metal Catalysts, Science 286 (1999) 49.

[3] J. Pan, S. Lu, Y. Li, A. Huang, L. Zhuang, J. Lu, High-Performance Alkaline Polymer Electrolyte for Fuel Cell Applications, Advanced Functional Materials 20 (2010) 312-319.

[4] J. Wu, H. Yang, Platinum-Based Oxygen Reduction Electrocatalysts, Accounts of Chemical Research 46 (2013) 1848-1857.

[5] R. Wu, Y. Xue, X. Qian, H. Liu, K. Zhou, S.H. Chan, J.N. Tey, J. Wei, B. Zhu, Y. Huang, Pt nanodendrites anchored on bamboo-shaped carbon nanofiber arrays as highly efficient electrocatalyst for oxygen reduction reaction, International Journal of Hydrogen Energy 38 (2013) 16677-16684.

[6] S.-I. Choi, S. Xie, M. Shao, J.H. Odell, N. Lu, H.-C. Peng, L. Protsailo, S. Guerrero, J. Park, X. Xia, J. Wang, M.J. Kim, Y. Xia, Synthesis and Characterization of $9 \mathrm{~nm}$ Pt-Ni Octahedra with a Record High Activity of $3.3 \mathrm{~A} / \mathrm{mgPt}$ for the Oxygen Reduction Reaction, Nano Letters 13 (2013) 3420-3425.

[7] T. Cochell, W. Li, A. Manthiram, Effects of Pt Coverage in Pt@PdCu5/C CoreShell Electrocatalysts on the Oxygen Reduction Reaction and Methanol Tolerance, The Journal of Physical Chemistry C 117 (2013) 3865-3873.

[8] B. Lim, M. Jiang, P.H.C. Camargo, E.C. Cho, J. Tao, X. Lu, Y. Zhu, Y. Xia, Pd-Pt Bimetallic Nanodendrites with High Activity for Oxygen Reduction, Science 324 (2009) 1302-1305.

[9] G. Wu, P. Zelenay, Nanostructured Nonprecious Metal Catalysts for Oxygen Reduction Reaction, Accounts of Chemical Research 46 (2013) 1878-1889.

[10] G. Wu, K.L. More, P. Xu, H.-L. Wang, M. Ferrandon, A.J. Kropf, D.J. Myers, S. Ma, C. M. Johnston, P. Zelenay, A carbon-nanotube-supported graphene-rich nonprecious metal oxygen reduction catalyst with enhanced performance durability, Chemical Communications 49 (2013) 3291-3293.

[11] Z. Chen, D. Higgins, A. Yu, L. Zhang, J. Zhang, A review on non-precious metal electrocatalysts for PEM fuel cells, Energy \& Environmental Science 4 (2011) 3167-3192.

[12] C.W.B. Bezerra, L. Zhang, K. Lee, H. Liu, A.L.B. Marques, E.P. Marques, H. Wang, J Zhang, A review of $\mathrm{Fe}-\mathrm{N} / \mathrm{C}$ and $\mathrm{Co}-\mathrm{N} / \mathrm{C}$ catalysts for the oxygen reduction reaction, Electrochimica Acta 53 (2008) 4937-4951.

[13] B. Genorio, D. Strmcnik, R. Subbaraman, D. Tripkovic, G. Karapetrov, V.R. Stamenkovic, S. Pejovnik, N.M. Marković, Selective catalysts for the hydrogen oxidation and oxygen reduction reactions by patterning of platinum with calix [4] arene molecules, Nat Mater 9 (2010) 998-1003.

[14] Y. Liang, Y. Li, H. Wang, J. Zhou, J. Wang, T. Regier, H. Dai, Co3O4 nanocrystals on graphene as a synergistic catalyst for oxygen reduction reaction, Nat Mater 10 (2011) 780-786. 
[15] H.-S. Oh, J.-G. Oh, B. Roh, I. Hwang, H. Kim, Development of highly active and stable non-precious oxygen reduction catalysts for PEM fuel cells using polypyrrole and a chelating agent, Electrochemistry Communications 13 (2011) 879-881.

[16] G.S. Parkinson, Z. Novotny, G. Argentero, M. Schmid, J. Pavelec, R. Kosak, P. Blaha, U. Diebold, Carbon monoxide-induced adatom sintering in a Pd-Fe3O4 model catalyst, Nat Mater 12 (2013) 724-728.

[17] Q. Yu, L.A. Jauregui, W. Wu, R. Colby, J. Tian, Z. Su, H. Cao, Z. Liu, D. Pandey, D. Wei, T.F. Chung, P. Peng, N.P. Guisinger, E.A. Stach, J. Bao, S.-S. Pei, Y.P. Chen, Control and characterization of individual grains and grain boundaries in graphene grown by chemical vapour deposition, Nat Mater 10 (2011) 443-449.

[18] H. Zhang, T. Watanabe, M. Okumura, M. Haruta, N. Toshima, Catalytically highly active top gold atom on palladium nanocluster, Nat Mater 11 (2012) 4952.

[19] T. Huang, S. Mao, H. Pu, Z. Wen, X. Huang, S. Ci, J. Chen, Nitrogen-doped graphene-vanadium carbide hybrids as a high-performance oxygen reduction reaction electrocatalyst support in alkaline media, Journal of Materials Chemistry A 1 (2013) 13404-13410.

[20] S. Mao, Z. Wen, T. Huang, Y. Hou, J. Chen, High-performance bi-functional electrocatalysts of 3D crumpled graphene-cobalt oxide nanohybrids for oxygen reduction and evolution reactions, Energy \& Environmental Science 7 (2014) 609-616.

[21] T. Huang, S. Mao, G. Zhou, Z. Wen, X. Huang, S. Ci, J. Chen, Hydrothermal synthesis of vanadium nitride and modulation of its catalytic performance for oxygen reduction reaction, Nanoscale 6 (2014) 9608-9613.

[22] R. Wu, Y. Xue, X. Qian, H. Liu, K. Zhou, S.H. Chan, J.N. Tey, J. Wei, B. Zhu, Y. Huang, Pt nanodendrites anchored on bamboo-shaped carbon nanofiber arrays as highly efficient electrocatalyst for oxygen reduction reaction, International Journal of Hydrogen Energy 38 (2013) 16677-16684.

[23] E. Biddinger, D. Deak, U. Ozkan, Nitrogen-Containing Carbon Nanostructures as Oxygen-Reduction Catalysts, Top Catal 52 (2009) 1566-1574.

[24] S. Chen, J. Bi, Y. Zhao, L. Yang, C. Zhang, Y. Ma, O. Wu, X. Wang, Z. Hu, NitrogenDoped Carbon Nanocages as Efficient Metal-Free Electrocatalysts for Oxygen Reduction Reaction, Advanced Materials 24 (2012) 5593-5597.

[25] J. Han, L.L. Zhang, S. Lee, J. Oh, K.-S. Lee, J.R. Potts, J. Ji, X. Zhao, R.S. Ruoff, S. Park, Generation of B-Doped Graphene Nanoplatelets Using a Solution Process and Their Supercapacitor Applications, ACS Nano 7 (2012) 19-26.

[26] K.S. Novoselov, A.K. Geim, S.V. Morozov, D. Jiang, Y. Zhang, S.V. Dubonos, I.V. Grigorieva, A.A. Firsov, Electric Field Effect in Atomically Thin Carbon Films, Science 306 (2004) 666-669.

[27] K.S. Novoselov, V.I. Fal'ko, L. Colombo, P.R. Gellert, M.G. Schwab, K. Kim, A roadmap for graphene, Nature 490 (2012) 192-200.

[28] Z. Yang, Z. Yao, G. Li, G. Fang, H. Nie, Z. Liu, X. Zhou, X.a. Chen, S. Huang, SulfurDoped Graphene as an Efficient Metal-free Cathode Catalyst for Oxygen Reduction, ACS Nano 6 (2011) 205-211.

[29] R. Imran Jafri, N. Rajalakshmi, S. Ramaprabhu, Nitrogen doped graphene nanoplatelets as catalyst support for oxygen reduction reaction in proton exchange membrane fuel cell, Journal of Materials Chemistry 20 (2010) 71147117.

[30] D. Wei, Y. Liu, Y. Wang, H. Zhang, L. Huang, G. Yu, Synthesis of N-Doped Graphene by Chemical Vapor Deposition and Its Electrical Properties, Nano Letters 9 (2009) 1752-1758.

[31] C.Z. Zhu, S.J. Dong, Recent progress in graphene-based nanomaterials as advanced electrocatalysts towards oxygen reduction reaction, Nanoscale 5 (2013) 1753-1767.

[32] U.I. Kramm, I. Herrmann-Geppert, S. Fiechter, G. Zehl, I. Zizak, I. Dorbandt, D. Schmei, P. Bogdanoff, Effect of iron-carbide formation on the number of active sites in Fe-N-C catalysts for the oxygen reduction reaction in acidic media, Journal of Materials Chemistry A (2013).

[33] D. Wang, X. Chen, D.G. Evans, W. Yang, Well-dispersed Co304/Co2MnO4 nanocomposites as a synergistic bifunctional catalyst for oxygen reduction and oxygen evolution reactions, Nanoscale 5 (2013) 5312-5315.

[34] K. Gong, F. Du, Z. Xia, M. Durstock, L. Dai, Nitrogen-Doped Carbon Nanotube Arrays with High Electrocatalytic Activity for Oxygen Reduction, Science 323 (2009) 760-764.

[35] L.S. Panchakarla, A. Govindaraj, C.N.R. Rao, Boron- and nitrogen-doped carbon nanotubes and graphene, Inorganica Chimica Acta 363 (2010) 4163-4174.

[36] L. Yang, S. Jiang, Y. Zhao, L. Zhu, S. Chen, X. Wang, Q. Wu, J. Ma, Y. Ma, Z. Hu, Boron-Doped Carbon Nanotubes as Metal-Free Electrocatalysts for the Oxygen Reduction Reaction, Angewandte Chemie 123 (2011) 7270-7273.

[37] Y. Zheng, Y. Jiao, L. Ge, M. Jaroniec, S.Z. Qiao, Two-Step Boron and Nitrogen Doping in Graphene for Enhanced Synergistic Catalysis, Angew Chem Int Edit 52 (2013) 3110-3116.

[38] Y. Tang, B.L. Allen, D.R. Kauffman, A. Star, Electrocatalytic Activity of NitrogenDoped Carbon Nanotube Cups, Journal of the American Chemical Society 131 (2009) 13200-13201.

[39] H.W. Zhu, C.L. Xu, D.H. Wu, B.O. Wei, R. Vajtai, P.M. Ajayan, Direct Synthesis of Long Single-Walled Carbon Nanotube Strands, Science 296 (2002) 884-886.
[40] Z. Liu, X. Lin, J.Y. Lee, W. Zhang, M. Han, L.M. Gan, Preparation and Characterization of Platinum-Based Electrocatalysts on Multiwalled Carbon Nanotubes for Proton Exchange Membrane Fuel Cells, Langmuir 18 (2002) 4054-4060.

[41] Z. Wang, R. Jia, J. Zheng, J. Zhao, L. Li, J. Song, Z. Zhu, Nitrogen-Promoted SelfAssembly of N-Doped Carbon Nanotubes and Their Intrinsic Catalysis for Oxygen Reduction in Fuel Cells, ACS Nano 5 (2011) 1677-1684.

[42] Z. Chen, D. Higgins, Z. Chen, Nitrogen doped carbon nanotubes and their impact on the oxygen reduction reaction in fuel cells, Carbon 48 (2010) 30573065.

[43] Y. Ma, L. Sun, W. Huang, L. Zhang, J. Zhao, Q. Fan, W. Huang, Three-Dimensional Nitrogen-Doped Carbon Nanotubes/Graphene Structure Used as a Metal-Free Electrocatalyst for the Oxygen Reduction Reaction, The Journal of Physical Chemistry C 115 (2011) 24592-24597.

[44] Z.-J. Lu, S.-J. Bao, Y.-T. Gou, C.-J. Cai, C.-C. Ji, M.-W. Xu, J. Song, R. Wang, Nitrogen-doped reduced-graphene oxide as an efficient metal-free electrocatalyst for oxygen reduction in fuel cells, RSC Advances 3 (2013) 39903995.

[45] P.H. Matter, E. Wang, J.-M.M. Millet, U.S. Ozkan, Characterization of the Iron Phase in CNx-Based Oxygen Reduction Reaction Catalysts, The Journal of Physical Chemistry C 111 (2007) 1444-1450.

[46] T.C. Nagaiah, S. Kundu, M. Bron, M. Muhler, W. Schuhmann, Nitrogen-doped carbon nanotubes as a cathode catalyst for the oxygen reduction reaction in alkaline medium, Electrochemistry Communications 12 (2010) 338-341.

[47] N. Al-Aqtash, I. Vasiliev, Ab Initio Study of Boron- and Nitrogen-Doped Graphene and Carbon Nanotubes Functionalized with Carboxyl Groups, The Journal of Physical Chemistry C 115 (2011) 18500-18510.

[48] Z.-H. Sheng, H.-L. Gao, W.-J. Bao, F.-B. Wang, X.-H. Xia, Synthesis of boron doped graphene for oxygen reduction reaction in fuel cells, Journal of Materials Chemistry 22 (2012) 390-395.

[49] S. Maldonado, S. Morin, K.J. Stevenson, Structure, composition, and chemical reactivity of carbon nanotubes by selective nitrogen doping, Carbon 44 (2006) $1429-1437$.

[50] G. Wu, D. Li, C. Dai, D. Wang, N. Li, Well-Dispersed High-Loading Pt Nanoparticles Supported by Shell-Core Nanostructured Carbon for Methanol Electrooxidation, Langmuir 24 (2008) 3566-3575.

[51] G. Wu, R. Swaidan, D. Li, N. Li, Enhanced methanol electro-oxidation activity of PtRu catalysts supported on heteroatom-doped carbon, Electrochimica Acta 53 (2008) 7622-7629.

[52] D. Wang, H.L. Xin, R. Hovden, H. Wang, Y. Yu, D.A. Muller, F.J. DiSalvo, H.D. Abruña, Structurally ordered intermetallic platinum-cobalt core-shell nanoparticles with enhanced activity and stability as oxygen reduction electrocatalysts, Nat Mater 12 (2013) 81-87.

[53] T. Sharifi, G. Hu, X. Jia, T. Wågberg, Formation of Active Sites for Oxygen Reduction Reactions by Transformation of Nitrogen Functionalities in Nitrogen-Doped Carbon Nanotubes, ACS Nano 6 (2012) 8904-8912.

[54] H.L. Fei, R.Q. Ye, G.L. Ye, Y.J. Gong, Z.W. Peng, X.J. Fan, E.L.G. Samuel, P.M. Ajayan, J.M. Tour, Boron- and Nitrogen-Doped Graphene Quantum Dots/Graphene Hybrid Nanoplatelets as Efficient Electrocatalysts for Oxygen Reduction, ACS Nano 8 (2014) 10837-10843.

[55] Q. Sun, Z. Li, D.J. Searles, Y. Chen, G. Lu, A. Du, Charge-Controlled Switchable CO2 Capture on Boron Nitride Nanomaterials, Journal of the American Chemical Society 135 (2013) 8246-8253.

[56] J.D. Baran, H. Grönbeck, A. Hellman, Analysis of Porphyrines as Catalysts for Electrochemical Reduction of $\mathrm{O} 2$ and Oxidation of $\mathrm{H} 2 \mathrm{O}$, Journal of the American Chemical Society 136 (2013) 1320-1326.

[57] X. Wang, K.M. Liew, Density Functional Study of Fluorinated Single-Walled Silicon Carbide Nanotubes, The Journal of Physical Chemistry C 116 (2011) $1702-1708$.

[58] E. Cruz-Silva, F. Lo'pez-Uri'as, E. Munoz-Sandoval, B.G. Sumpter, H. Terrones, J.C. Charlier, V. Meunier, M. Terrones, Electronic Transport and Mechanical Properties of Phosphorus- and Phosphorus-Nitrogen-Doped Carbon Nanotubes, ACS Nano 3 (2009) 1913-1921.

[59] H. Wang, T. Maiyalagan, X. Wang, Review on Recent Progress in NitrogenDoped Graphene: Synthesis, Characterization, and Its Potential Applications, ACS Catalysis 2 (2012) 781-794.

[60] Y. Li, Y. Zhao, H. Cheng, Y. Hu, G. Shi, L. Dai, L. Qu, Nitrogen-Doped Graphene Quantum Dots with Oxygen-Rich Functional Groups, Journal of the American Chemical Society 134 (2011) 15-18.

[61] H.M. Jeong, J.W. Lee, W.H. Shin, Y.J. Choi, H.J. Shin, J.K. Kang, J.W. Choi, Nitrogen-Doped Graphene for High-Performance Ultracapacitors and the Importance of Nitrogen-Doped Sites at Basal Planes, Nano Letters 11 (2011) 2472-2477.

[62] X. Kong Q Chen, Z Sun, Enhanced Oxygen Reduction Reactions in Fuel Cells on H-Decorated and B-Substituted Graphene, Chemphyschem 14 (2013) 514-519.

[63] X.-k. Kong, Q.-w. Chen, Z. Sun, The positive influence of boron-doped graphyne on surface enhanced Raman scattering with pyridine as the probe molecule and oxygen reduction reaction in fuel cells, RSC Advances 3 (2013) 4074-4080. 